\title{
Patrimônio Cultural e Políticas Culturais
}

\author{
Cultural Heritage and Cultural Policy
}

\author{
Cristiane Bartz de Àvila1; Dra. Maria de Fatima Bento Ribeiro²; Ma. Ângela Mara Bento \\ Ribeiro $^{3}$
}

1 crisbartz40@yahoo.com.br, Prefeitura Municipal de Pelotas; ${ }^{2}$ angetur.ribeiro8@gmail.com, Universidade Federal do Pampa; ${ }^{3}$ mfabento@ hotmail.com, Universidade Federal de Pelotas.

\begin{abstract}
Resumo
O presente trabalho tem por objetivo analisar como as políticas culturais relacionadas aos estudos sobre o Patrimônio Cultural Imaterial tem se desenvolvido ao longo destes últimos anos. Sabemos que as primeiras iniciativas de preservação do patrimônio estavam atreladas ao patrimônio material, o qual denominamos "pedra e cal”. A partir de discussões sobre a valorização de culturas dos grupos denominados "minorias"1, há uma preocupação com o patrimônio imaterial, tais como danças e saberes-fazeres.
\end{abstract}

Palavras-Chave: Políticas Culturais, Patrimônio Cultural, Legislação.

\begin{abstract}
This study aims to analyze how cultural policies related to studies of the Intangible Cultural Heritage has developed over recent years. We know that the first heritage preservation initiatives were linked to material heritage, which we call "bricks and mortar". From discussions on the appreciation of cultures of groups called "minorities," there is concern for intangible heritage, such as dances and know-doings.
\end{abstract}

Keywords: Cultural Policy, Cultural Heritage, Legislation.

\section{Introdução}

Atualmente surgem no campo dos estudos interdisciplinares diversas pesquisas sobre o Patrimônio Cultural de uma forma mais universalizada, ou seja, não somente levando em conta os monumentos de "pedra e cal", como acontecia até a década de 80 do século XX. Sabemos que essa mudança é "lenta e gradual" usando o mesmo trocadilho quanto às referências da abolição da escravidão. Algumas leis e iniciativas vêm contribuindo para fixar a ideia de que o Patrimônio Cultural é formado por um conjunto de elementos que não dissociam patrimônio material e patrimônio imaterial. Salientamos que os estudos e discussões sobre esta temática abrangem cada vez mais espaços nos meios intelectuais, destacando-se que no ano de 2013 se cumpriram 10 anos da Convenção do Patrimônio Imaterial da UNESCO. Em 2003, os países membros sistematizaram diretrizes para tratar da temática do Patrimônio Cultural Imaterial numa dinâmica diferente do que vinha até então sendo adotado em relação ao Patrimônio Material. O governo brasileiro promulgou, no mesmo ano da Convenção do Patrimônio Imaterial, a lei 10639/2003², que torna obrigatório o estudo do continente africano e da cultura afro-brasileira nas escolas de ensino básico, públicas e particulares, principalmente nas disciplinas de História, Educação Artística e Literatura.

\footnotetext{
${ }^{1}$ Sobre o uso do termo "minoritários", ver Appadurai (2009).

${ }^{2}$ Esta lei foi substituída pela Lei 11645/2008 para incluir o estudo da história e da cultura indígena.
} 
Podemos perceber o início de um movimento voltado às políticas públicas em relação aos grupos "minoritários"3 no Brasil, a partir da Constituição de 1988, com os artigos 215 e 216, os quais mencionam ser o patrimônio cultural brasileiro constituído pela natureza material e imaterial, e fazem referência à valorização das manifestações culturais das mais diversas etnias, das quais podemos inferir a indígena, a afro-brasileira, a alemã, a italiana, a francesa, a japonesa, enfim, os mais diversos segmentos que constituem a população brasileira. Nessa questão, podemos dizer que os conflitos de memória podem geralmente estar representados nas diversas manifestações do patrimônio cultural das diferentes sociedades ao longo da história da humanidade e neste sentido, no Brasil, faz pouco mais de uma década que foi publicado o decreto $3551 / 2000^{4}$ referente à proteção do Patrimônio Cultural Imaterial através de seu registro em quatro livros específicos.

Até a II Guerra Mundial, o mundo Ocidental preocupou-se em selecionar, proteger, guardar, e conservar monumentos associados ao patrimônio material. Somente após esse período é que países asiáticos e do Terceiro Mundo começaram a trazer reflexões sobre a preservação de natureza imaterial, não tão importante por sua materialidade, mas por suas criações populares, expressões de conhecimentos, práticas, processos culturais, modo de relacionamento com o meio ambiente, etc.

Os países de Terceiro Mundo reivindicaram em 1972, junto à UNESCO, um instrumento de proteção às manifestações populares de valor cultural, e, em 1989, o órgão responde através da Recomendação sobre a Salvaguarda da Cultura Tradicional e Popular, que sugere aos países membros a identificação, a salvaguarda, a conservação, a difusão e a proteção da cultura tradicional e popular por meio de registros, inventários, suporte econômico, introdução de seu conhecimento no sistema educativo, documentação e proteção à propriedade intelectual dos grupos detentores de conhecimentos tradicionais.

No Brasil, o precursor das ideias de patrimônio imaterial foi Mário de Andrade, pois já nos anos 30, quando esteve ligado ao Serviço do Patrimônio Histórico e Artístico Nacional (SPHAN), elaborou um projeto em que falava das artes arqueológicas e ameríndia, que compreendia não apenas artefatos colecionáveis, mas também paisagens e folclore. Suas ideias naquela época não foram avante, mas o intelectual documentou suas viagens ao Nordeste longo de sua vida, em fotografias, gravações e filmes. Outro personagem que influenciou bastante e produziu vários trabalhos sobre o patrimônio cultural brasileiro foi Aloísio Magalhães ${ }^{5}$, quando fundou o Centro Nacional de Referência Cultural (CNRC) na década de 1970.

Os instrumentos de reconhecimento e valorização criados pelo governo brasileiro levam em conta a natureza dinâmica e processual dos bens, promovendo uma interação dos aspectos materiais e imateriais do patrimônio cultural brasileiro.

Nessa perspectiva é que estudos sobre o Patrimônio Cultural, e especialmente o Patrimônio Cultural Imaterial, têm sido trabalhados ao longo destes 10 anos, aprimorando-se

\footnotetext{
${ }^{4}$ No Brasil, as políticas públicas de valorização do Patrimônio Cultural Imaterial tiveram, aparentemente, uma trajetória anterior à Convenção do Patrimônio Imaterial de 2003.

5 Aloísio Sérgio Barbosa de Magalhães (Recife, PE, 1927 - Pádua, Itália, 1982) foi pintor, designer, gravador, cenógrafo, figurinista. Bacharel em Direito pela Faculdade de Direito da Universidade Federal de Pernambuco, obtém bolsas do governo francês e norte-americano para se aperfeiçoar nas áreas de museus e artes gráficas. Em 1960, volta ao Brasil e abre um escritório voltado à comunicação visual e desenho industrial e realiza projetos para empresas e órgãos públicos. Com o prestígio amealhado junto a figuras de destaque do governo federal, é nomeado, em 1979, diretor do Instituto do Patrimônio Histórico e Artístico Nacional - IPHAN e, no ano seguinte, presidente da Fundação Nacional Pró-Memória, conforme IPHAN (2014, pg. 07).
} 
cada vez mais as discussões do papel exercido pelos atores sociais envolvidos, sejam eles comunidades, órgãos governamentais ou ONGs.

\section{Objetivo geral}

O presente trabalho tem com intenção tecer uma discussão sobre as políticas de proteção do patrimônio cultural, e em especial do patrimônio imaterial que tem recebido nestas últimas décadas um destaque importante, tendo em vistas as discussões que permeiam a valorização das manifestações culturais dos grupos denominados "minoritários".

\section{Fundamentos Teóricos}

Como fundamentação teórica, tomaremos por base as discussões sobre a legislação brasileira, tais como a própria constituição de 1988, que a partir dos artigos 215 e 216, entram no mérito da questão da valorização cultural e patrimonial. Também faremos uma análise do decreto 3551/2000 que trata do registro dos bens culturais de natureza imaterial e finalmente traremos para a discussão a Convenção sobre o patrimônio cultural imaterial.

A partir dessa análise tentaremos dialogar com autores como Appadurai(2009) e Tomaz Tadeu da Silva(2000), os quais o primeiro nos fala que devemos respeitar o "outro", as diferenças e dar voz social aos mesmos e o segundo trabalha questões de identidades, as quais tem sido discutidas na perspectiva dos grupos "minoritários", como já foi citado anteriormente neste texto.

\section{Palavras Finais}

Em nossas palavras finais, gostaríamos de salientar que nossa intenção foi demonstrar um histórico de algumas políticas públicas que discutem sobre a importância de se valorizar o patrimônio cultural imaterial, como representação de manifestações culturais de grupos denominados "minoritários". Através do diálogo com os autores procuraremos embasar nosso texto, trabalhando o porquê da escolha e da relevância do tema. Acreditamos que se obteve um avanço significativo com o reconhecimento, estudos, discussões e implementação de políticas de proteção ao patrimônio cultural como um todo, sejam eles materiais, imateriais ou naturais.

\section{Referências}

APPADURAI, Arjun. O Medo ao Pequeno Número: ensaio sobre a geografia da raiva. São Paulo: Iluminuras: Itaú Cultural, 2009.

BRASIL.1988.Constituição da República Federativa do Brasil. Brasília, DF, Senado.

. 2000. Registro de bens culturais de natureza imaterial. Decreto - lei $n^{\circ} 3551$, de 4 de agosto de 2000. [em linha]. Disponível em:

http://www.planalto.gov.br/ccivil_03/decreto/D3551.htm consultado em 05/11/2012.

Lei 10639/2003. Ensino da Cultura afro-brasileira na rede de ensino, de 9 de janeiro de 2003. Disponível em: http://www.planalto.gov.br/ccivil_03/leis/2003/110.639.htm .

Lei 11645/2008. Ensino da Cultura afro-brasileira e indígena na rede de ensino, de 10 de março de 2008. Disponível em: http://www.planalto.gov.br/ccivil_03/_ato20072010/2008/lei/111645.htm .

SILVA, Tomaz Tadeu da Silva (Org). Identidade e Diferença: a perspectiva dos estudos culturais. 4.ed. Petrópolis, RJ: Vozes, 2000. 
UNESCO. Convenção sobre a proteção do Patrimônio Mundial Cultural e Natural, 1972. Disponível em: http://whc.unesco.org/archive/convention-pt.pdf .

UNESCO. Convenção para salvaguarda do Patrimônio Cultural Imaterial, 2003.

Disponível em: http://portal.iphan.gov.br/baixaFcdAnexo.do?id=379 . 